\title{
PENGARUH HANDLING CUSTOMER COMPLAINTS DAN KEPERCAYAAN PELANGGAN TERHADAP LOYALITAS KONSUMEN GOJEK PADA MAHASISWA UNIVERSITAS PENDIDIKAN GANESHA DI SINGARAJA
}

\author{
A. B. Sinulingga ${ }^{1}$, N. L. W. S. Telagawathi ${ }^{2}$ \\ 1,2 Jurusan Manajemen, Universitas Pendidikan Ganesha,Singaraja \\ e-mail: viomita1234@gmailcom, gemilangsuryawan@gmail.com
}

\begin{abstract}
Abstrak
Penelitian ini bertujuan untuk menguji dampak dari: (1) handling customer complaints terhadap loyalitas konsumen, (2) kepercayaan pelanggan terhadap loyalitas konsumen, (3) handling customer complaints dan kepercayaan pelanggan terhadap loyalitas konsumen pada mahasiswa Universitas Pendidikan Ganesha di Singaraja. Desain penelitian yang digunakan dalam penelitian ini adalah kuantitatif kausal. Objek penelitian ini adalah handling customer compliants, kepercayaan pelanggan dan loyalitas konsumen. Subjek penelitian adalah mahasiswa Universitas Pendidikan Ganesha pelanggan Gojek. besar sampel sebanyak 90 orang. Pengumpulan data dilakukan dengan kuesioner dan dianalisis dengan analisis regresi linear berganda. Hasilnya menunjukkan: (1) handling customer complaints berpengaruh positif dan signifikan terhadap loyalitas konsumen (2) kepercayaan pelanggan berpengaruh positif dan signifikan terhadap loyalitas konsumen, dan (3) handling customer complaints dan kepercayaan pelanggan berpengaruh signifikan terhadap loyalitas konsumen.
\end{abstract}

Kata kunci:, handling customer complaints, kepercayaan pelanggan, loyalitas konsumen

\section{Abstract}

This study aimed at examining the effect of: (1) handling customer complaints toward consumer loyalty,(2) customer trust toward consumer loyalty, (3) handling customer complaints and customer trust toward consumer loyalty Gojek to college student Ganesha University of Education. The research design of this study was causal quantitative research. The object of this research were the handling customer complaints, customer trust and consumer loyalty. The subject of this research were college student Ganesha University of Education customer Gojek. The total sampel of this study were 95 people. The data collection of this study were questionnaire and multiple linear regresion analysis. The results showed that: (1) handling customer complaints has a positive and significant effect toward consumer loyalty, (2) customer trust has a positive and significant effect toward consumer loyalty, (3) handling customer complaints and customer trust have a significant effect toward consumer loyalty.

Keywords: ${ }^{-}$consumer loyalty, customer trust, handling customer complaints

\section{Pendahuluan}

Di era teknologi yang semakin modern tercermin perilaku masyarakat yang berbeda dari era sebelumnya. Intensitas teknologi di berbagai aspek kehidupan menjadikan masyarakat dituntut untuk meningkatkan mobilitas. Hal ini berdampak pada kebutuhan sarana transportasi yang dapat berpindah dengan cepat dari satu tempat ke tempat lain meski jaraknya jauh. Saat ini terdapat terobosan baru yaitu inovasi transportasi berbasis aplikasi online yang didukung oleh teknologi komunikasi smartphone yaitu integrasi dari sepeda motor dan teknologi komunikasi. Pertumbuhan bisnis transportasi online semakin cepat. Hal ini dapat dilihat dari banyaknya transportasi online seperti Gojek, Grab, dan Uber. Persaingan transportasi online sudah mulai ketat dan masing-masing berlomba memberikan layanan berkualitas, harga terjangkau dan menarik konsumen tepat waktu.

Konsumen adalah pengguna barang / jasa yang tersedia di masyarakat, untuk kepentingan diri sendiri, keluarganya, orang lain dan makhluk hidup lainnya (Yuniarti, 2015). Definisi lain dari konsumen adalah orang yang membutuhkan, menggunakan, memanfaatkan dan mengkonsumsi barang atau jasa dari perusahaan. Hampir seluruh 
lapisan masyarakat sudah menggunakan jasa transportasi online baik dalam pemesanan makanan ataupun bepergian dengan jarak dekat atau jauh karena sangat praktis dan mudah. Untuk tetap berada dalam persaingan bisnis dan berupaya meningkatkan keberhasilan suatu perusahaan maka perlu adanya loyalitas konsumen.

Loyalitas konsumen merupakan situasi konsumen memiliki sikap positif terhadap produk atau layanan, disertai dengan model pembelian kembali yang konsisten. Syaifullah (2018) mengemukakan bahwa loyalitas konsumen dibentuk oleh berbagai tahapan pembelajaran yang diperoleh konsumen dalam komunikasi antara konsumen dengan produk atau penyedia jasa. Kemampuan perusahaan untuk memenangkan persaingan tidak hanya terletak pada produk yang mereka sediakan, karena pelanggan juga memilih perusahaan yang mereka yakini dapat merespon dengan cepat, mengedepankan semangat, dapat dipercaya dan respon tepat waktu terhadap keluhan pelanggan (penanganan keluhan). Sehingga mempengaruhi kepuasan pelanggan, kepercayaan dan loyalitas (Yap, BW, dll, 2012). Selain itu pelanggan juga berharap agar perusahaan dapat merespon keluhan tentang bagaimana mengatasi ketidakpuasan pelanggan terhadap produk (Goodwin and Ross, 1990).

Penelitian ini dilakukan di kota Singaraja dimana sedang berkembang transportasi online Gojek diduga karena terdapat handling customer complaints yang kurang maksimal, seperti respond dari perusahaan yang lambat terhadap konsumen, sulit bagi konsumen untuk mengajukan complaint dan situs pengajuan complain belum berfungsi secara maksimal. Selain itu, pada Data Top Brand index Tahun 2016 s.d 2019 terdapat penurunan kepercayaan pelanggan. Begitu juga dengan dengan loyalitas pelanggan yang berkurang terlihat pada observasi awal yang telah dilakukakan sebelumnya pada mahasiswa Universitas Pendidikan Ganesha bahwa banyak mahasiswa yang beralih ke transportasi online lainnya. Pada umumnya, perusahaan yang tidak mampu menghadapi perusahaan pesaing yaitu perushaan yang memiliki loyalitas konsumen rendah. Oleh sebab itu, sebuah organisasi harus mengetahui fakor-faktor yang mempengaruhi loyalitas konsumen agar dapat memberikan kontribusi kepada perusahaan secara maksimal.

Loyalitas konsumen secara umum ditentukan oleh hal berikut yaitu kepercayaan, komitmen, komunikasi dan penanganan keluhan mempengaruhi loyalitas konsumen (Murti, 2013). Tejaningtyas (2015) menyatakan bahwa kualitas pelayanan, penanganan komplain dan citra perusahaan mempengaruhi loyalitas. Penanganan keluhan, kepercayaan dan kepuasan mempengaruhi loyalitas konsumen (Suryani, 2017). Penelitian Ningtyas (2011) menyatakan kepercayaan, komitmen, komunikasi, penanganan masalah dan kepuasan mempengaruhi loyalitas konsumen. Jadi dapat disimpulkan variabel-variabel yang mempengaruhi loyalitas konsumen adalah kepercayaan, komitmen, komunikasi, penanganan keluhan, citra perusahaan, kualitas pelayanan, dan kepuasan. Pada penelitian ini memfokuskan variabel penanganan keluhan pelanggan (handling customer complaints) dan kepercayaan pelanggan, karena pada penelitian sebelumnya terdapat hasil riset yang berbeda sehingga peneliti melakukan penelitian kembali variabel penanganan keluhan pelanggan, kepercayaan pelanggan dan loyalitas konsumen.

Handling customer complaints Dalam memenuhi harapan dari konsumen maka pihak gojek harus mengatasi masalah atau rasa tidak puas dari pelanggan terhadap produk atau jasa yang diberikan perusahaan dengan ramah. Hal ini akan membantu perusahaan untuk mempertahankan konsumennya sehingga pada saat melakukan handling customer complaints yang baik dan mudah akan berpengaruh terhadap loyalitas konsumen. Pernyataan ini sejalan dengan penelitian yang dilakukan oleh Suryani (2017) yang menyatakan bahwa complaints handling mempunyai pengaruh positif dan signifikan terhadap loyalitas konsumen. Namun berbeda dengan penelitian Supit et al. (2015) dan penelitian Tejaningtyas (2015) yang menyatakan bahwa complainst handling mempunyai pengaruh positif terhadap loyalitas pelanggan namun tidak signifikan. Penelitian Ningtyas (2011) juga yang menyatakan bahwa penanganan masalah/keluhan tidak berpengaruh terhadap loyalitas konsumen.

Penanganan keluhan yang dilakukan oleh perusahaan Gojek masih tergolong rendah. Diketahui bahwa rendahnya penanganan keluhan dikarenakan, kurangnya empati 
perusaahn terhadap konsumen, lambatnya respon terhadap konsumen dan kurangnya keadilan terhadap masalh yang dihadapi konsumen. Selain handling customer complaints, kepercayaan pelanggan juga merupakan variabel yang mempengaruhi loyalitas konsumen. Pada saat konsumen sudah percaya terhadap produk dan jasa otomatis akan membuat konsumen loyal, sehingga jika kepercayaan pelanggan yang tinggi dan positif akan meningkatkan loyalitas konsumen. Pernyataan ini sesuai dengan penelitian Syaifullah (2018) menyatakan bahwa kepercayaan mempunyai pengaruh yang signifikan positif terhadap loyalitas konsumen. Namun berbeda dengan penelitian yang dilakukan Pratiwi (2015) menyatakan bahwa kepercayaan mempunyai pengaruh signifikan negatif terhadap loyalitas konsumen. Uraian diatas menunjukkan inkonsintensi penelitian terdahulu dan teori yang dikemukan oleh Meylisa dan Gies (2017) menyatakan bahwa jika complaints handling dan kepercayaan tidak baik maka loyalitas konsumen juga tidak baik dan sebaliknya. Hasil riset terdahulu dan teori menjadi dasar perlunya dilakukan penelitian kembali tentang variabel complaints handling, kepercayaan dengan loyalitas konsumen. Berdasarkan uraian di atas maka fokus penelitian yaitu handling customer complaints, kepercayaan pelanggan dan loyalitas konsumen.

\section{Metode}

Penelitian ini menggunakan desain penelitian kuantitatif kausal. Tahapan penelitian kausal kuantitatif meliputi (1) perumusan masalah, (2) landasan teori, (3) perumusan hipotesis, (4) penelitian, (5) pengumpulan dan analisis data, dan (6) pelaporan dan inferensi. Tiga variabel yang digunakan dalam penelitian ini yaitu penanganan keluhan pelanggan (X1), kepercayaan pelanggan (X2), dan loyalitas konsumen (Y). Subjek penelitian ini adalah mahasiswa Universitas Pendidikan Ganesha klien Gojek. Sedangkan subjek penelitian ini adalah keluhan pelanggan, kepercayaan pelanggan dan loyalitas konsumen. Sampel yang digunakan dalam penelitian ini berjumlah 90 orang. Selain itu, pengumpulan data dilakukan dengan teknik kuisioner kemudian dianalisis dengan menggunakan analisis regresi linier berganda.Dan pengujian hiotesis yang digunakan yaitu uji secara parsial (uji t) dan uji secara simultan (uji f).

\section{Hasil dan Pembahasan}

Hasil pengujian yang diperoleh dari analisis regresi linier berganda pengaruh $\mathrm{X} 1$ dan $\mathrm{X} 2$ terhadap $Y$ seperti terlihat pada Tabel 1, hubungan struktural pengaruh $X 1$ dan $X 2$ terhadap Y ditunjukkan pada Gambar 1, kontribusi pengaruh X1 dan X2 pada Y seperti yang terlihat pada Tabel 2. Hasil Perhitungan pada Tabel 1 menunjukkan X1 dan X2 melalui $Y$ dengan pengaruh masing-masing variabeldapat digambarkan pada Gambar 1.

Tabel. 1

Output SPSS Analisis regresi linear berganda Pengaruh Handling Customer Complaints dan Kepercayaan Pelanggan Terhadap Loyalitas Konsumen Gojek pada Mahasiswa Universitas Pendidikan Ganesha di SIngaraja.

\begin{tabular}{|c|c|c|c|c|c|}
\hline Parameter & Nilai & $\begin{array}{c}P- \\
\text { Value }\end{array}$ & $\begin{array}{c}\text { Alpha } \\
(\alpha)\end{array}$ & Keputusan & Simpulan \\
\hline $\operatorname{Ryx}_{1} x_{2}$ & 0,427 & 0,000 & 0,05 & Menolak $\mathrm{H}_{0}$ & $\begin{array}{l}\text { Ada pengaruh simultan dari } \\
\text { handling customer complaints dan } \\
\text { kepercayaan pelanggan terhadap } \\
\text { loyalitas konsumen. }\end{array}$ \\
\hline $\mathrm{R}^{2} \mathrm{yx}_{1} \mathrm{x}_{2}$ & 0,182 & - & - & - & $\begin{array}{l}\text { Menunjukkan } \\
\text { sumbangan pengaruh secara } \\
\text { simultan dari handling customer } \\
\text { complaints dan kepercayaan } \\
\text { pelanggan terhadap loyalitas } \\
\text { konsumen sebesar } 18,2 \% \text {. }\end{array}$ \\
\hline
\end{tabular}




\begin{tabular}{|c|c|c|c|c|c|}
\hline Parameter & Nilai & $\begin{array}{c}P- \\
\text { Value }\end{array}$ & $\begin{array}{l}\text { Alpha } \\
(\alpha)\end{array}$ & Keputusan & Simpulan \\
\hline$\varepsilon$ & 0,164 & - & - & - & $\begin{array}{l}\text { Menunjukkan besarnya pengaruh } \\
\text { variabel lain sebesar } 16,4 \% \text {. }\end{array}$ \\
\hline $\mathrm{Pyx}_{1}$ & 0,306 & 0,000 & 0,05 & Menolak $\mathrm{H}_{0}$ & $\begin{array}{l}\text { Ada pengaruh parsial dari handling } \\
\text { customer complaints terhadap } \\
\text { loyalitas konsumen. }\end{array}$ \\
\hline$P^{2} \mathrm{yx}_{1}$ & 0,089 & - & - & - & $\begin{array}{l}\text { Menunjukkan } \\
\text { sumbangan pengaruh parsial dari } \\
\text { handling customer complaints } \\
\text { terhadap loyalitas konsumen } \\
\text { sebesar } 8,9 \% \text {. }\end{array}$ \\
\hline $\mathrm{Pyx}_{2}$ & 0,304 & 0,000 & 0,05 & Menolak $\mathrm{H}_{0}$ & $\begin{array}{l}\text { Ada pengaruh parsial dari } \\
\text { kepercayaan pelanggan terhadap } \\
\text { loyalitas konsumen. }\end{array}$ \\
\hline$P^{2} \mathrm{yx}_{2}$ & 0,094 & - & - & - & $\begin{array}{lr}\text { Menunjukkan } & \text { besarnya } \\
\text { sumbangan } & \text { pengaruh } \\
\text { kepercayaan pelanggan terhadap } & \text { loyalitas konsumen sebesar } 9,4 \% \text {. }\end{array}$ \\
\hline$A$ & 3,132 & 0,011 & 0,05 & Signifikan & $\begin{array}{l}\text { Bisa memprediksi tingkat loyalitas } \\
\text { konsumen. }\end{array}$ \\
\hline$b_{1}$ & 0,297 & 0,003 & 0,05 & Signifikan & $\begin{array}{l}\text { Bisa memprediksi tingkat loyalitas } \\
\text { konsumen. }\end{array}$ \\
\hline$b_{2}$ & 0,273 & 0,003 & 0,05 & Signifikan & $\begin{array}{l}\text { Bisa memprediksi tingkat loyalitas } \\
\text { konsumen. }\end{array}$ \\
\hline
\end{tabular}

Berdasarkan hasil uji statistik analisis regresi linear berganda dengan menggunakan program SPSS 20.0 for Windows, maka diperoleh struktur pengaruh handling customer complaints dan kepercayaan pelanggan terhadap loyalitas konsumen seperti pada Gambar.1

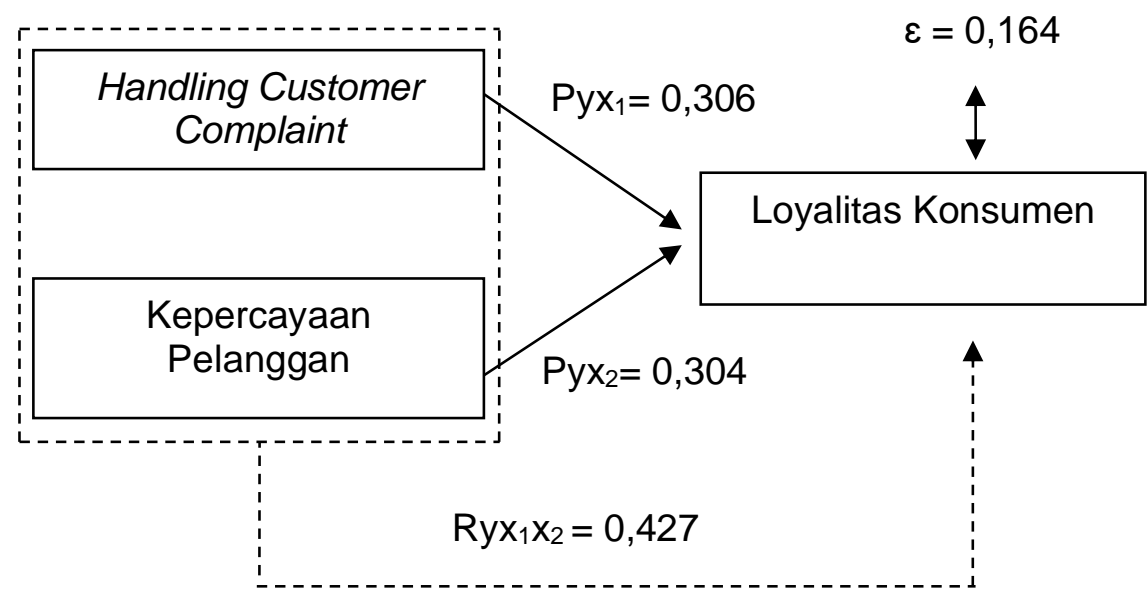

Gambar.1

Struktur Pengaruh Handling Customer Complaints (X1) dan Kepercayaan Pelanggan (X2) terhadap Loyalitas Konsmen $(\mathrm{Y})$

Berdasarkan hasil uji analisis regresi linier berganda yang tertera pada tabel.1, nilai konstanta $(\alpha)$ yang diperoleh yaitu sebesar 3,132. Selanjutnya, untuk nilai koefisien regresi handling customer complaint $\left(b_{1}\right)$ sebesar 0, 297 dan nilai koefisien kepercayaan pelanggan 
$\left(b_{2}\right)$ sebesar 0,273 . Dari hasil tersebut, maka persamaan regresi dapat diformulasikan adalah

$$
Y=3,132+0,297 X_{1}+0,273 X_{2}
$$

Persamaan regresi tersebut menyatakan bahwan ilai konstanta sebesar 3,132 artinya adalah jika handling customer complaint $\left(\mathrm{X}_{1}\right)$ dan kepercayaan pelanggan $\left(\mathrm{X}_{2}\right)$ nilainya sama dengan nol, maka loyalitas konsumen $(Y)$ sebesar 3,132. Nilai koefisien handling customer complaint $\left(b_{1}\right)$ yaitu sebesar 0,297 , artinya bahwa setiap kenaikan variabel handling customer complaint satu satuan maka variabel loyalitas konsumen meningkat sebesar 0,297 sehingga menjadi 3,132 (3,132+0,297), dengan asumsi bahwa variabel bebas yang lainnya tetap. Nilai koefisien kepercayaan pelanggan $\left(b_{2}\right)$ sebesar 0,273 berarti bahwa setiap kenaikan variabel kepercayaan pelanggan satu satuan maka variabel loyalitas konsumenn meningkat sebesar 0,273 sehingga menjadi $3,132 \quad(3,132+$ 0,273 ) dengan asumsi bahwa variabel bebas yang lainnya tetap.

Penggunaan analisis regresi berganda sebagai metode analisis untuk mengetahui dampak penanganan keluhan dan kepercayaan pelanggan terhadap loyalitas pelanggan. Baik pengaruh langsung maupun tidak langsung dari masing-masing variabel tersebut. Besar kecilnya input langsung dan tidak langsung dari X1 dan X2 di Y ditunjukkan pada Tabel. 2

Tabel.2

Sumbangan Pengaruh Variabel

(X1) dan (X2) terhadap (Y)

\begin{tabular}{lll}
\hline \multicolumn{1}{c}{ Keterangan } & Besar Sumbangan & Persentase (\%) \\
\hline $\begin{array}{l}\text { Besar pengaruh langsung } \\
\text { X1 terhadap } Y\end{array}$ & 0,306 & $30,6 \%$ \\
$\begin{array}{l}\text { Besar pengaruh tidak langsung X1 } \\
\text { terhadap Y }\end{array}$ & 0,089 & $8,9 \%$ \\
$\begin{array}{l}\text { Besar pengaruh langsung } \\
\text { X2 terhadap Y }\end{array}$ & 0,304 & $30,4 \%$ \\
$\begin{array}{l}\text { Besar pengaruh tidak langsung X2 } \\
\text { terhadap } Y\end{array}$ & 0,094 & $9,4 \%$ \\
$\begin{array}{l}\text { Besar pengaruh total X1 dan X2 } \\
\text { terhadap Y } \\
\text { Besar pengaruh factor lain } \\
\text { terhadap } Y\end{array}$ & 0,472 & $47,2 \%$ \\
\hline
\end{tabular}

Berdasarkan hasil penelitian pada tabel 2 menunjukkan bahwa ada pengaruh hadling customer complaint terhadap loyalitas konsumen. Besar pengaruh hubungan hadling customer complaint terhadap loyalitas konsumen adalah 30,6\% kemudian besar sumbangan pengaruh dari kepercayaan pelanggan terhadap loyalitas adalah 30,4\%. Berdasarkan hasil perhitungan uji statistik yang nampak pada Tabel menunjukkan bahwa hadling customer complaint dan kepercayaan pelanggan secara bersama-sama berpengaruh terhadap loyalitas konsumen Gojek di Singaraja. Besar sumbangan pengaruh hadling customer complaint dan kepercayaan pelanggan terhadap loyalitas konsumen sebesar 42,7\% sedangkan sebesar $16,4 \%$ merupakan pengaruh faktor lain. Temuan ini memberikan implikasi bahwa hadling customer complaint dan kepercayaan pelanggan merupakan upaya untuk meningkatkan loyalitas konsumen Gojek.

Ditinjau dari hasil uji analisis regresi linier berganda yang telah dipaparkan sebelumnya, dapat diketahui bahwa ada pengaruh positif dan signifikan dari variabel handling customer complaint dan variabel kepercayaan pelanggan terhadap loyalitas konsumen Gojek di Singaraja. Hasil ini sesuai dengan penelitian Tejaningtyas (2015) 
menyatakan bahwa penanganan komplain dan kepercayaan pelanggan mempengaruhi loyalitas konsumen. Penanganan keluhan dan kepercayaan mempengaruhi loyalitas konsumen (Suryani, 2017). Penelitian Ningtyas (2011) menyatakan kepercayaan dan penanganan keluhan mempengaruhi loyalitas konsumen.

Hasil uji analisis berikutnya menunjukkan bahwa, ada pengaruh dari kepercayaann pelanggan terhadap loyalitas konsumen. Hal ini sejalan dengan teori yang dikemukakan Meylisa dan Gies (2017) berpendapat bahwa jika complaints handling dan kepercayaan tidak baik maka loyalitas konsumen juga tidak baik dan sebaliknya. Oleh karenanya, perusahaan perlu memerhatikan kepercayaan pelanggan demi mendapatkan kesetiaan atau loyalitas dari konsumen. Disamping hal itu, penelitian ini juga sesuai dengan hasil penelitian yang dilakukan oleh Suryani (2017) yang menyatakan bahwa complaints handling mempunyai pengaruh positif dan signifikan terhadap loyalitas konsumen. Dari hasil penelitian dapat dilihat pula sumbangan pengaruh yang diperoleh cukup besar. Artinya, indikatorindikator variabel handling customer complaint dan kepercayaan pelanggan pada survei ini dapat digunakan untuk mengetahui seberapa besar loyalitas konsumen Gojek di Singaraja. Apa, loyalitas konsumen adalah situasi di mana konsumen bersikap positif terhadap suatu produk atau layanan dan disertai dengan pola pembelian berulang yang konsisten. Syaifullah (2018) menyimpulkan bahwa loyalitas konsumen adalah sesuatu yang dibentuk oleh berbagai tahapan pembelajaran yang diperoleh konsumen melalui pertukaran antara konsumen dan pemasok produk atau jasa.

Selain melihat besar sumbangan pengaruh dari hubungan variabel- variabel tersebut, dapat dilihat pula pada data responden berdasarkan jenis kelamin bahwa jumlah responden perempuan lebih banyak dibandingkan jumlah responden laki-laki. Hal ini menunjukkan bahwa tingkat antusiasme responden yang berjenis kelamin perempuan cenderung tinggi dalam mengisi kuesioner dibandingkan responden laki-laki yang menggunakan Gojek di Singaraja. Begitupula dengan data berdasarkan semester responden, yang mana presentase paling tinggi yaitu semester 4 kemudian semester 2 dan yang memiiki persentasi yang terendah yaitu semester 6. Hal ini menunjukkan mahasiswa semester tersebut cenderung peduli terhadap handling customer complaint dan kepercayaan pelanggan serta loyalitas konsumen. Oleh sebab itu, mahasiswa semester 4 lebih banyak bersedia mengisi kuesioner yang diberikan. Pada semester 2 dan 6 terdapat kemungkinan orang lebih cenderung memerhatikan segala sesuatu yang dapat membuat mereka nyaman dan loyal terhadap suatu perusahaan, termasuk handling customer complaint dan kepercayaan pelanggan. Tidak hanya itu saja, jika dilihat dari data responden berdasarkan fakultas/jurusan maka jumlah mahasiswa yang paling banyak mengisi kuesioner adalah dari FOK. Kemudian responden terbanyak lainnya adalah FIP, FBS, FHIS. Ini menunjukkan bahwa responden yang berasal dari FOK dan FIP, FBS, dan FHIS cenderung lebih memerhatikan handling customer complaint, kepercayaan pelanggan dan loyalitas konsumen pada Gojek pada mahasiswa Universitas Pendidikan Ganesha di Singaraja.

Berdasarkan hasil dan pembahasan penelitian yang diperoleh, maka implikasi dari adanya penelitian ini dapat dilihat baik secara akademis dan praktis. Hasil penelitian menunjukkan bahwa ada pengaruh dari handling customer complaint dan kepercayaann pelanggan terhadap loyalitas konsumen Gojek di Singaraja dengan sumbangan pengaruh yaitu sebesar $18,2 \%$. Secara akademis, penelitian ini menambah bukti empiris serta memperkaya pemahanman di bidang pemasaran dan manajemen layanan, khususnya tentang pengaruh handling customer complaints dan kepercayaan pelanggan terhadap loyalitas konsumen Gojek di Singaraja. Hasil penelitian ini juga menunjukkan bahwa perusahaan harus tetap memerhatikan handling customer complaint dan tingkat kepercayaann pelanggan untuk mendapatkan loyalitas konsumen. Perusahaan yang memiliki complaints handling dan kepercayaan tidak baik maka loyalitas konsumen juga tidak baik dan sebaliknya (Meylisa dan Gies, 2017). Artinya, ketika perusahaan tidak menghiraukan atau tidak memerhatikan handling customer complaint dan kepercayaann pelanggannya, maka pelanggan cenderung tidak percaya dan tidak loyal terhadap perusahaan tersebut. Dengan demikian, tentu adanya kemungkinan untuk pelanggan beralih dan menggunakan produk atau jasa dari perusahaan lain. Selain itu, hasil penelitian 
diperoleh bahwa handling customer complaint berpengaruh terhadap loyalitas konsumen Gojek di Singaraja. Sumbangan pengaruh yang diperoleh yaitu sebanyak 8,9\%. Hasil tersebut berimplikasi pada pihak operasional Gojekl agar terus mempertahankan bahkan perlu meningkatkan handling customer complaint. Untuk mencapai tujuan tersebut, tentunya ada upaya dan program yang dilakukan oleh pihak Gojek.

Secara praktis, upaya yang dapat dilakukan untuk meningkatkan handling customer complaint yaitu meminimalisir terjadinya keluhan dari konsumen. Ketika Gojek masih merasakan adanya keluhan baik dari aplikasi ataupun kinerja dari para driver maka hal itu dapat membentuk persepsi yang tidak baik terkait pelayanan Gojek secara keseluruhan. Oleh sebab itu, pihak Gojek perlu melakukan pemeriksaan dan pembaharuan aplikasi secara berkala. Tidak hanya itu saja, meningkatkan profesionalisme para driver dalam melayani pelanggan juga perlu dioptimalkan. Upaya lainnya yang dapat dilakukan yaitu menyebarkan informasi atau mensosialisasikan kepada konsumen bahwa perusahaan atau dalam hal ini adalah Gojek telah memenuhi tanggung jawab sosial terhadap lingkungan dan masyarakat. Adapun program yang dapat ditawarkan untuk menstimulus upaya-upaya tersebut yaitu dengan membuatkan jadwal pemeriksaan aplikasi Gojek secara berkala dan selanjutnya dilakukan pembaharuan aplikasi. Program berikutnya yaitu mengadakan pelatihan dan pengembangan skill para staff secara rutin agar sejalan dengan SOP (Standar Operational Procedure) yang telah ditentukan. Perusahaan juga dapat membuat program untuk menambah promo bagi konsumen Gojek. Hal ini memungkinkan dapat menarik minat konsumen untuk menggunkan kembali Gojek.

Begitu pula dengan hasil penelitian berikutnya yang menyatakan bahwa ada pengaruh dari kepercayaan pelanggan terhadap loyalitas konsumen Gojek di Singaraja. Besar sumbangan pengaruh yang diperoleh yaitu 9,4\%. Hasil ini berimplikasi terhadap kinerja perusahaan agar senantiasa memberikan pelayanan yang terbaik, sehingga pelanggan percaya atas apa yang mereka inginkan. Dampak yang cenderung terjadi ketika kepercayaan pelanggan tidak terpenuhi secara maksimal yaitu timbulnya perasaan kecewa dari pelanggan. Jika hal itu terjadi, maka kepercayaan pelanggan atas kinerja perusahaan cenderung menurun. Tidak hanya itu, dampak lain yang mungkin terjadi adalah peralihan pelanggan ke perusahaan lain. Oleh sebab itu, pihak Gojek sangat perlu memerhatikan kepercayaan dari pelanggan untuk tetap menjaga loyalitas konsumen.

Adapun upaya yang dapat dilakukan untuk dapat memenuhi kepercayaan pelanggan adalah meminimalisir indikasi akan adanya keluhan dari konsumen Gojek. Sebaiknya para driver yang bertugas perlu memeriksa terlebih dahulu kendaraan secara detail sebelum menerima orderan dari konsumen. Upaya selanjutnya ialah meningkatkan kemampuan driver dalam berkomunikasi, memberikan pelayanan, bahkan dapat menangani keluhan konsumen yang ada. Tidak hanya itu saja, para driver harus selalu ramah selama melakukan pelayanan kepada konsumen. Hal itu cenderung membuat konsumen merasa nyaman selama perjalanan atau memesan makanan. Namun, apabila terjadi keluhan maka pihak Gojek hendaknya melakukan evaluasi dan berusaha menindaklanjuti keluhan tersebut. Program yang dapat dilakukan dalam upaya menjaga dan meningkatkan kepercayaan pelanggan Gojek ialah mengadakan pelatihan dan pengembangan terhadap karyawan. Hal itu bertujuan untuk menjaga kualitas kinerja karyawan agar mampu melayani pelanggan dengan baik. Dapat juga dilakukan program outting guna meningkatkan semangat kerja dan solidaritas driver. Dari adanya program tersebut, maka driver mendapat penyegaran, mereka tidak jenuh dalam bekerja dan pada akhirnya dapat memberikan pelayanan yang optimal kepada konsumen. Dengan demikian, indikasi kurangnya kepercayaan dari pelanggan bisa berkurang.

\section{Simpulan dan Saran}

Simpulan dari penelitian menunjukkan bahwa handling customer complaints berpengaruh positif dan signifikan terhadap loyalitas konsumen Gojek pada mahasiswa Universitas Pendidikan Ganesha di Singaraja, kepercayaan pelanggan berpengaruh positif dan signifikan terhadap loyalitas konsumen Gojek pada mahasiswa Universitas Pendidikan 
Ganesha di Singaraja dan handling customer complaints dan kepercayaan pelanggan berpengaruh positif dan signifikan terhadap loyalitas konsumen Gojek pada mahasiswa Universitas Pendidikan Ganesha di Singaraja.

Saran dari penelitian bagi peneliti selanjutnya dapat menggunakan variabel-variabel lainnya yang dapat memengaruhi loyalitas konsumen berdasarkan teori-teori yang ada. Dan menguji menggunakan analisis yang lain dan bagi perusahaan, hasil penelitian yang telah diperoleh saat ini dapat menjadi bahan pertimbangan dan evaluasi untuk operasional transportasi online, meningkatkan handling customer complaints dan kepercayaan pelanggan baik oleh manajer Gojek ataupun transportasi online secara umum sehingga akan menambah loyalitas konsumen.

\section{Daftar Pustaka}

Meylisa, Riri dan Gies Aprisia. 2017. "Pengaruh Citra Perusahaan (Corporate Image) dan Penangan Keluhan (Complaint Handling) terhadap Loyalitas Pelanggan (Loyalty) Natasha Skin Care di Kota Padang".

Murti, Sasanti Herdina. 2013. "Pengaruh Dimensi Relationship Marketing terhadap Loyalitas Pelanggan”. Management Analysis Journal, ISSN 2252-6552.

Ningtyas, Fitri dan Basuki Rachmad. 2011. "Pengaruh Kepercayaan, Komitmen, Komunikasi, Penanganan Masalah dan Kepuasan Nasabah terhadap Loyalitas Nasabah Bank Muamalat di Surabaya". Journal of Business and Banking. Vol. 1 No. 1.

Pratiwi, Detha Misgi, dkk.2015. “ The Influence of Brand Image, Brand Trust and Customer Satisfaction on Brand Loyalty (Case of Samsung Smartphone)". Jurnal Berkala IImiah Efisiensi, Vol. 15 No. 05.

Supit, Soleman Juan, dkk. 2015. " The Influence of Trust, Commitment, Communication, and Handling of Complaints Toward Customer Loyalty at Otomoto Manado". Jurnal EMBA, Vol. 3 No. 2, ISSN 2303-1174.

Supit, Juan Soleman. 2015. "The Influence of Trust, Commitment, and Handling of Complaints Toward Customer Loyalty at Tonado Manado". Jurnal EMBA, Vol. 3 No. 2. ISSN 23031174.

Suryani, Dwi Ayu. 2017. "The Influence of Complaint Handling, Trust, and Satisfaction to Member Loyalty at Woman Cooperative 'Sejarah' Gayam Village Gurah Districts". Artikel Skripsi, Vol. 01 No.05.

Syafullah. 2018. "Pengaruh Kepercayaan dan Komunikasi terhadap Loyalitas Pelanggan pada PT Spectrum Lintas Service di Kota Batam". JIM UPB, Vol. 6 No. 1.

Tejaningtyas, Ruth Andita Hayu. 2015. "Pengaruh Kualitas Pelayanan, Penanganan Komplain dan Citra Perusahaan terhadap Loyalitas Nasabah dengan Kepuasan Nasabah sebagai Variabel Mediasi (Studi pada PT, AIA Finansial Cabang Surakarta)". Riset Manajemen dan Akuntansi, Vol. 6 No. 2. 